\title{
O papel do Enterococcus Faecalis no tratamento das infecções endodônticas
}

\section{The role of Enterococcus Faecalis in the treatment of endodontical infections}

\author{
Fernanda Chaves Coelho ${ }^{1}$ \\ Renato Pial PeReira ${ }^{2}$ \\ ROGÉRIO VIEIRA SILVA ${ }^{3}$
}

\begin{abstract}
RESUMO
Objetivo: Abordar o papel do Enterococcus Faecalis no tratamento das infecções endodônticas, por meio de uma revisão de literatura, incluindo os seus principais fatores de virulência e os procedimentos mais eficazes para a sua eliminação.

Métodos: Foram catalogadas pesquisas ex vivo, relatos de casos clínicos, revisões sistemáticas com metaanálise e revisão de literatura. Foram incluídos artigos publicados nos últimos 12 anos a partir de buscas nas principais bases de dados mundiais, Pubmed, Scielo e Google Schoolar.

Conclusão: Foi possível constatar que as principais hipóteses atribuídas ao fracasso endodôntico por enterococcus faecalis são a capacidade de formar biofilme, utilização da bomba de prótons, entre outros mecanismos, tornando-os resistentes, tendo como métodos clínicos mais recentes para a sua erradicação o uso de soluções com associação da irrigação ultrassônica passiva, medicações intracanais e terapia fotodinâmica.
\end{abstract}

Palavras-chaves: Cavidade Oral. Enterococcus faecalis. Endodontia. Fatores de virulência. Proliferação.

\section{ABSTRACT}

Objective: To address the role of Enterococcus Faecalis in the treatment of endodontic infections, through a review of the literature, including its main virulence factors and the most effective procedures for its elimination.

Methods: Ex vivo research, clinical case reports, systematic reviews with meta-analysis and literature review were cataloged. It was included articles published in the last 12 years from searches in the main databases worldwide, Pubmed, Scielo and Google Schoolar.

Conclusion: It was possible to verify that the main hypotheses attributed to endodontic failure by enterococcus faecalis are the ability to form biofilm, use of the proton pump, among other mechanisms, making them resistant, having as the most recent clinical methods for their eradication the use of solutions with association of passive ultrasonic irrigation, intracanal medications and photodynamic therapy.

Keywords: Enterococcus faecalis. Persistent infection. Endodontic infection. Endodontic. Root canal.

Graduada em Odontologia, Faculdade Independente do Nordeste - FAINOR, Vitória da Conquista, BA, Brasil.

Mestre em Endodontia, Universidade Estadual do Sudoeste da Bahia. Departamento de Odontologia. Jequié, BA, Brasil.

Doutor em Odontologia, Faculdade Independente do Nordeste - FAINOR, Vitória da Conquista, BA, Brasil. 


\section{INTRODUÇÃO}

Os microrganismos presentes nas infecções pulpares e perirradiculares são, em sua grande maioria, advindos de túbulos dentinários expostos por cárie, traumas, trincas e desgaste da superfície do esmalte. Além disso, podem ser provenientes de comunicações pulpares diretas, de restaurações inadequadas ou de selamento coronário insatisfatório após o tratamento endodôntico, funcionando como via de comunicação aos canais radiculares. Esses microrganismos encontrados são com frequência anaeróbios estritos e facultativos, sendo estes mais resistentes à atividade antimicrobiana, e podendo ser a causa de insucesso no tratamento endodôntico. ${ }^{1}$

Entre as causas que levam ao fracasso da terapia endodôntica, destaca-se o biofilme, que coloniza o complexo sistema de canais radiculares (SCR): Istmos, deltas apicais, canais secundários, canais recorrentes ou canais em forma de "c", que dificultam o acesso para instrumentação, a ação das substâncias irrigadoras e da medicação intracanal. Também podem estar relacionadas à técnica utilizada, bem como, à má conduta profissional e/ou falhas na biossegurança durante o procedimento, originando infecções secundárias e/ou persistentes. ${ }^{2,3}$

A microbiota presente nessas infecções normalmente se compõe por uma única espécie, com predominância de bactérias anaeróbias gram-positivas e ocasionalmente gram-negativas. O enterococcus faecalis tem sido citado como a espécie de maior prevalência em infecções secundárias e persistentes. Isso ocorre devido à sua capacidade de se adaptar a condições hostis e ao seu potencial para formação de fatores de virulência, podendo manter a sua viabilidade por até doze meses na falta de nutrientes. ${ }^{3,4,5}$
Dessa forma, os fatores de virulência podem estar associados à competência na formação de microcolônias, em que os microrganismos aderem à superfície e auxiliam no crescimento e colonização bacteriana. Além disso, são capazes de utilizar a bomba de prótons para preservar a acidez da célula, fato que a torna resistente aos efeitos das medicações. Também possuem a parede celular formada por ácido lipoteicoico e presença de adesinas bacterianas, que permitem o contato direto entre a bactéria e o hospedeiro. ${ }^{5,6}$

Partindo desses pressupostos, este trabaIho teve por objetivo, por meio da revisão de literatura, elucidar o papel do enterococcus faecalis no tratamento das infecções endodônticas, abordar os seus principais fatores de virulência, as dificuldades que são encontradas na realização da terapêutica e os métodos clínicos mais recentes para a sua erradicação.

\section{Metodologia}

A presente revisão de literatura foi embasada em uma pesquisa bibliográfica, em três principais bases de dados mundiais, Pubmed, Scielo e Google Schoolar, tendo como inclusão: artigos em inglês, espanhol e português, abrangendo pesquisas in e ex vivo, relatos de casos clínicos associados à pesquisa, revisões sistemáticas com metanálise e revisão de literatura, publicados nos últimos 12 anos (2008 a 2019). Foram excluídos teses, monografias, dissertações, livros e capítulos de livros.

Para refinamento das buscas, foram pesquisados descritores na língua portuguesa, espanhola e inglesa: Enterococcus faecalis; Endodontia; Endodontic infection; Fatores de virulência; Persistent infection; Irrigación manual convencional; Root canal. 


\section{REVISÃo de LITERATURA}

\section{Infecções endodônticas}

Relacionada a fatores microbianos, a infecção primária é considerada como a infecção inicial, presente antes do controle bacteriano pelo cirurgião dentista e, que, pode ter sido causada por micro-organismos presentes nos primeiros estágios de invasão pulpar. $^{8}$ Esse controle tem por objetivo a erradicação total ou a diminuição do número de micro-organismos presentes no SCR por meio do preparo químico-mecânico. ${ }^{7}$

Quando a terapêutica endodôntica não é eficaz na neutralização da microbiota, o conceito de insucesso endodôntico é atribuído, denominando assim de infecção secundária com prevalência de bactérias que não são encontradas na infecção primária e que contaminaram o canal após a intervenção profissional. ${ }^{3,8}$ A infecção persistente, por sua vez, possui micro-organismos tanto da infecção primária quanto da secundária que se manteve apesar dos procedimentos de desinfecção, pela ação de instrumentos manuais, soluções irrigadoras e medicações intracanais. $^{8}$

A dificuldade na neutralização desses micro-organismos pode ser, em parte, pela anatomia interna do sistema de canais radiculares composto por deltas apicais, canais acessórios, entre outros, que dificultam a ação de substâncias antimicrobianas utilizadas na irrigação e medicação intracanal. ${ }^{2,3}$

\section{Enterococcus Faecalis e fatores de virulência}

O Enterococcus faecalis é um microorganismo anaeróbio facultativo gram positivo, comumente encontrado em infecções endodônticas, sendo a espécie de maior prevalência em infecções secundárias e persistentes, com prevalência de até $90 \%{ }^{3}$ Colonizam os canais radiculares, provavelmente utilizando os fluidos provenientes dos tecidos de suporte do dente, osso alveolar e ligamento periodontal. ${ }^{6,11}$ Devido aos seus fatores de virulência, ou seja, qualquer constituinte do micro-organismo capaz de causar ou potencializar danos ao hospedeiro, essa espécie é capaz de invadir o sistema de canais radiculares e se adaptar a condições hostis quando submetidos a tensões subletais. ${ }^{7,8,9,10}$

Diferente de outras espécies, possui a habilidade de penetrar nos túbulos dentinários, se aderir ao colágeno, formar biofilme, e se desenvolvem em condições limitantes com poucos nutrientes, aumentando os mecanismos de resistência, o que confere uma maior citotoxidade, dificultando a sua remoção e a ação de agentes antimicrobianos. ${ }^{5,6}$ Além disso, sobrevive em $\mathrm{pH}$ alcalino, fato que pode ser explicado pela presença da bomba de prótons que mantém o pHácido como forma de proteção do citoplasma bacteriano. Crescem em temperaturas de $35^{\circ} \mathrm{C}$, porém, resistem a temperaturas de $10^{\circ} \mathrm{C}$ a $45^{\circ} \mathrm{C}$, caracterizando fatores importantes na manutenção da infecção, após a terapêutica endodôntica. ${ }^{5,6,11}$

As enzimas líticas gelatinase, produzidas pelas células do hospedeiro, são capazes de hidrolisar o colágeno e regular a formação e remodelação tecidual diante de processos fisiológicos. Em casos de elevadas quantidades de enterococcus faecalis, essas enzimas aumentam e o colágeno hidrolisado se torna responsável pela patogênese e danos periapicais. Já a substância de agregação é uma adesina bacteriana proteica que permite o contato entre a bactéria e o hospedeiro por meio de uma substância ligante que facilita a troca de plasmídeo. A associação entre essas duas substâncias representa atividade de superantígeno, capazes de liberar uma quantidade inespecífica de células de defesa que irão atuar na reabsorção óssea e destruição celular. ${ }^{5,6,11}$

\section{Soluções Irrigadoras}

Devido à toxicidade, as bactérias, presentes em todo SCR são as principais causas de infecções pulpares e periapicais. Em razão da complexa anatomia dentária, torna-se essencial a limpeza completa para regressão dessas patologias. Embora exista 
uma variedade de técnicas de instrumentação, ainda assim é frequente a ocorrência de resíduos de tecidos pulpares, raspas de dentina e bactérias. Esses remanescentes podem servir de fontes nutritivas, mantendo os microorganismos ativos agredindo os tecidos. ${ }^{12}$

Aproximadamente $50 \%$ das paredes dos canais radiculares não são devidamente instrumentadas e limpas, pois a ação do instrumento se limita apenas à luz do canal. Por esse motivo, faz-se necessário a combinação da instrumentação mecânica e química no intuito de potencializar a desinfecção. ${ }^{12}$

A solução irrigante ideal deve possuir, essencialmente, propriedades antibacterianas, habilidade de dissolver tecidos necróticos, baixa tensão superficial, solubilidade, baixa toxicidade para os tecidos e capacidade de remover a smear layer. ${ }^{12}$ Como principais soluções utilizadas em endodontia, destacamse o Ácido Etilenodiamino Tetracético (EDTA), o Hipoclorito de Sódio (NaOCL) e a Clorexidina $(\mathrm{CHX}){ }^{12,13}$

A ação da instrumentação mecânica libera raspas de dentina que se misturam ao tecido orgânico e substâncias químicas que impregnam na parede dentinária, formando uma camada residual que impede ou dificulta a limpeza do sistema de canais radiculares. Embora o hipoclorito de sódio seja um eficiente solvente, não é capaz de eliminar a matéria inorgânica. Por essa razão, o ácido Etilenodiamino Tetracético (EDTA) é um irrigante eficiente na remoção do componente inorgânico, sendo a ação quelante com maior uso na odontologia. ${ }^{16,17}$

Relatado pela primeira vez em 1792, na França, por Berthollet, o hipoclorito de sódio, constituído de uma mistura de hipoclorito de sódio e potássio, recebeu o nome de água de Javalle. Durante o período da Primeira Guerra Mundial, um químico inglês, Henry Dakin, formulou uma nova concentração de NaOCL a $0,5 \%$ utilizada, inicialmente, para desinfecção de feridas, denominando assim de solução de Dakin. Dois anos depois, Barret usou essa solução para irrigação dos canais radiculares, alegando um efetivo controle antisséptico. Já em 1936, foi publicado um artigo por Walker sobre irrigação do sistema de canais radiculares com NaOCL em uma concentração de $5 \%$ durante o preparo de dentes com necrose pulpar, uma vez que essa solução contribui para a eliminação dos agentes microbianos. ${ }^{13}$

Desde então, o hipoclorito de sódio tem sido o irrigante mais utilizado na prática clínica, com fortes atividades antimicrobianas e dissolução orgânica. Age dissolvendo a matéria, convertendo as substâncias insolúveis em solúveis para serem eliminadas durante a aspiração. Possui um ph altamente alcalino, que causa alterações no metabolismo celular, destruição de fosfolipídios e inibição na liberação de enzimas microbianas de forma irreversível. Pode ser encontrado em concentrações que variam de $0,5 \%$ a $5,25 \%$ para o emprego em endodontia. Quanto maior a concentração, tanto maior o seu poder de dissolução e neutralização de substâncias do SCR. Contudo, quanto maior a concentração, também tanto maior a agressão aos tecidos vivos perirradiculares, pois causam hemólise e ulceração, impedindo a ação de neutrófilos. ${ }^{13,14,15}$

Já a clorexidina tem sido utilizada, desde a década de 50, como um excelente agente antimicrobiano. Além da sua substantividade, ou seja, capacidade de se aderir à dentina e manter a sua ação por um prolongado período, possui também um amplo espectro de ação para combater tanto bactérias gram negativas quanto gram positivas. Dependendo da concentração, tem ação bactericida ou bacteriostática. Em altas concentrações, rompe a parede celular dos micro-organismos, conferindo efeito bactericida. Em baixas concentrações, inibe a função da membrana plasmática, resultando em uma ação bacteriostática, mantendo a sua 
substantividade por horas, após a aplicação. Isso pode ser explicado pela sua propriedade dicatiônica. Ou seja, uma ponta catiônica se liga à parte negativa do dente, e a outra ponta fica disponível para interagir com as bactérias. Além disso, é um irrigante com amplo espectro de ação, ativo contra anaeróbios facultativos, bactérias gram negativas, gram positivas, leveduras e fungos. ${ }^{12,24}$

Em um estudo realizado na Universidade de Passo Fundo, foram coletadas 50 raízes de pré-molares inferiores unirradiculares, em que foram divididos aleatoriamente em grupo controle negativo sem contaminação bacteriana e grupo controle positivo contaminados com cepas de enterococcus faecalis. Dessa forma, 15 amostras do grupo controle positivo receberam tratamento com gel de clorexidina $2 \%$ e outras 15 amostras com hipoclorito de sódio a $2,5 \%$. Os resultados mostraram que houve redução bacteriana semelhante entre o hipoclorito de sódio e a clorexidina, porém, não foi possível controlar totalmente a infecção do sistema de canais radiculares, mas as populações bacterianas foram reduzidas de forma significante. Existem razões para que as bactérias não fossem completamente eliminadas, e, uma delas está na incapacidade de o irrigante alcançar áreas consideradas inacessíveis. ${ }^{15}$

Irrigação ultrassônica passiva (PUI)

Como meio complementar na limpeza do SCR, a irrigação ultrassônica passiva foi relatada pela primeira vez por Weller e colaboradores, em 1980. Esse método se baseia na ativação de uma ponta de ultrassom no interior do canal radicular, preenchido anteriormente por solução irrigante, no limite do comprimento de trabalho. ${ }^{19}$ Devido à eficiente habilidade em colonizar túbulos dentinários, e sendo um dos principais agentes presentes em casos de insucesso endodôntico, o enterococcus faecalis tem sido o micro- organismo mais utilizado em estudos para avaliação da técnica de eliminação induzida por microfiltragem acústica ao redor da ponta ultrassônica. ${ }^{18,19}$

Dentescomumaanatomia complexapodem servir como abrigo para os remanescentes necróticos pulpares e biofilme bacteriano que podem atuar como um potencial para infecções persistentes. Como alternativa, a PUI tem demonstrado capacidade de remover dentina e tecidos orgânicos de áreas inacessíveis à instrumentação, pois permite que a solução irrigadora flua livremente, causando perturbação física do biofilme bacteriano. ${ }^{20}$

Em um estudo ex vivo para avaliar a efetividade da irrigação, foram coletados 75 dentes humanos inoculados com cepas de enterococcus faecalis durante 21 dias. Destes, cinco grupos foram divididos e irrigados com $\mathrm{PUI}+$ solução salina; $\mathrm{PUI}+\mathrm{NaOCl}$ a $1 \%$; Irrigação por agulha convencional + solução salina; Irrigação convencional + $\mathrm{NaOCl}$ a $1 \%$; sem irrigação. Todos os grupos foram irrigados por um período de dois minutos. Após 21 dias de incubação, as raízes foram novamente coletadas para avaliação. Houve relevante redução após a irrigação, no entanto, não houve diferenças estatísticas significantes entre os diferentes métodos de irrigação dos grupos. ${ }^{19}$

Em outro estudo composto por 64 amostras de dentes humanos contaminados por enterococcus faecalis, foram observados dois grupos de 30 amostras cada e um grupo contendo quatro amostras em que não foi usado método de irrigação. Um grupo contendo 30 amostras foi tratado pela técnica de irrigação convencional normal e o outro pela técnica de irrigação ultrassônica passiva. Houve uma taxa de sucesso utilizando da PUI de até $100 \%$ em relação à técnica manual, alcançando os terços dos canais radiculares previamente infectados. ${ }^{21}$ 


\section{Easy Clean}

Com os mesmos princípios de otimizar as substâncias químicas no interior dos canais radiculares por meio de agitação mecânica, um instrumento plástico, o easy clean (Easy Equipamentos Odontológicos, Belo Horizonte, Brasil) foi desenvolvido. O sistema easy clean é composto por uma ponta plástica, planejada para ativar o irrigante de forma mecânica combinado com um desenho de "asa de aeronave", com deformação insignificante das paredes do canal radicular, permitindo a introdução do instrumento até o comprimento de trabalho. Limpa por meio da agitação da solução irrigante e eliminação dos detritos aderidos nas paredes. É recomendado para uso em movimento reciprocante, ${ }^{22}$ porém, foi demonstrado que quando utilizado em rotação contínua para agitação da irrigação há uma maior eficácia na limpeza de istmos e paredes dos canais radiculares em comparação ao movimento reciprocante..$^{23,24}$

Em um estudo ex vivo para avaliar a eficácia do sistema easy clean versus a irrigação ultrassônica passiva, utilizando 10 molares inferiores, os espécimes foram divididos em grupos controle negativo, controle em branco e dois grupos experimentais: PUI e sistema easy clean. O sistema easy clean promoveu remoção de detritos mais eficaz nas regiões apicais dos canais radiculares em comparação à irrigação ultrassônica passiva. ${ }^{22}$

Para avaliar a capacidade de dissolução de matéria orgânica do canal radicular promovida por soluções irrigadoras e diferentes técnicas de agitação, uma amostra de 150 dentes bovinos foi utilizada. Independente do irrigante, o sistema easy clean promoveu uma maior capacidade de dissolução em comparação à irrigação mecânica e à irrigação ultrassônica passiva. ${ }^{25}$

\section{XP Endo Finisher}

$O$ instrumento $X P$ endo finisher (FKG, LaChaux-de-Fonds, Suíça) foi introduzido no intuito de melhoraralimpeza edescontaminação do canal radicular. Confeccionado com liga de níquel-titânico (NiTi) Max Wire. O instrumento, quando resfriado, é reto em sua fase Martensítica e, em contato com a temperatura corporal, muda para a fase Austenística, assumindo assim uma forma cônica de colher. No canal radicular, o instrumento é rotacionado e movido para cima e para baixo. Isso faz que o instrumento consiga tocar as paredes do canal radicular de uma forma mais eficaz e agitar a solução irrigadora no interior do SCR. Sugerese ser usado a $800 \mathrm{rpm}$ e $1 \mathrm{~N}$ de torque com soluções irrigantes, após a preparação do canal radicular por qualquer instrumento. ${ }^{26,27,28,29}$

Em um estudo in vitro, para avaliar a eficiência de três sistemas de irrigação, foram coletados 60 amostras de molares superiores, sendo que essas amostras foram divididas em três grupos de 20. O primeiro, foi ativado pelo sistema XP endo finisher, o segundo, pela PUI e, o terceiro, pelo sistema de irrigação sônica Endo Activador (Dentsply Tulsa Dental Especialidades, Tulsa, OK, EUA). Os três grupos foram ativados por um período de 60 segundos. Realizou-se a coleta dos dados e não houve diferenças significativas no terço coronal, médio e apical entre os grupos XP endo finisher e PUI, enquanto que diferenças estatísticas foram encontradas entre o sistema endo activador e ambos os grupos, PUI e $\mathrm{XP}$ endo finisher, que apresentaram canais significativamente mais limpos. No nível apical, o XP endo finisher mostrou uma menor quantidade de detritos em comparação aos outros grupos..$^{27,30}$

Em outro estudo para avaliar a eficiência da descontaminação do canal radicular utilizando instrumentos de níquel titânio, foram coletados 22 dentes molares inferiores previamente contaminados por enterococcus faecalis e submetidos ao preparo químico mecânico. Como sistemas de irrigação, foram utilizados a PUI e XP endo finisher. Os dois métodos 
apresentaram eficácia antibacteriana, sendo que apenas o XP endo finisher causou uma redução significativa na contagem bacteriana, após o preparo químico mecânico. ${ }^{26}$ Esses instrumentos proporcionam uma limpeza mais efetiva e pode ser utilizado em todos os casos.

\section{Terapia Fotodinâmica (PDT)}

Apesar dos avanços clínicos na área da endodontia e dos protocolos usados para a obtenção do sucesso na eliminação dos microorganismos do canal radicular, como limpeza mecânica, irrigação e medicações utilizando agentes antimicrobianos, o tratamento endodôntico pode resultar em falhas. ${ }^{31}$ Visto que uma correta limpeza intracanal aumenta consideravelmente as taxas de sucesso, protocolos recentes e efetivos têm sido relatados em literatura. ${ }^{32}$

Os lasers de baixa potência são mencionados como métodos em odontologia com finalidade terapêutica. Por não aumentarem a temperatura, não possuem efeito antimicrobiano associado. Todavia, quando utilizado em associação com algum agente fotossensibilizador, é capaz de reduzir a carga bacteriana. A junção de uma fonte de luz a um agente fotossensibilizador é denominada de terapia fotodinâmica. ${ }^{33}$ A terapia fotodinâmica é um método auxiliar na limpeza dos canais radiculares. Nessa técnica, usase um corante não tóxico, geralmente o azul de metileno com propriedade antibacteriana e antifúngica (fotossensibilizador) sendo, em sua grande maioria, com efeito de ação mais eficiente em bactérias gram positivas em comparação a gram negativas ${ }^{31} \mathrm{e}$, uma fonte luminosa de potência inferior a $100 \mathrm{~mW}$ sem geração de calor, ou seja, inferior a $10^{\circ} \mathrm{C}$, capaz de interagir com o fotossensibilizador para a formação de espécies reativas de oxigênio com potencial citotóxico e letal para os micro-organismos. A luz é responsável por excitar $\mathrm{o}$ agente fotossensibilizador.
Assim, o fotossensibilizador transfere energia ao oxigênio que é então transformado em oxigênio singleto, uma forma altamente reativa responsável pelo dano fotoquímico aos microorganismos. ${ }^{32,33}$

\section{Medicação Intracanal}

A escolha da medicação intracanal é uma das etapas mais importantes que contribuem para reparação tecidual em endodontia. Existem diferentes tipos de medicações capazes de agir na redução da carga bacteriana no interior do canal. Por possuírem duas importantes propriedades, antimicrobiana e indutora de reparo, o hidróxido de cálcio tem papel de destaque, sendo uma das medicações mais usadas como curativo de demora. Essas propriedades se desenvolvem como resultado da dissociação em íons cálcio e hidroxila que agem por meio de ações enzimáticas tanto nos tecidos, quanto nos micro-organismos, causando danos à membrana das bactérias, desnaturação proteica e danos ao DNA bacteriano. No entanto, o enterococcus faecalis é capaz de apresentar resistência sobre o hidróxido de cálcio, pois utiliza a bomba de prótons para manter o $\mathrm{PH}$ ácido, dificultando a alcalinização no interior da célula bacteriana. Devido à sua baixa fusão e solubilidade, o hidróxido de cálcio possui atividade limitada por agir somente em contato com os microorganismos. Para compensar as deficiências do hidróxido de cálcio, estudos apontam sucesso quando associado com outros veículos, como água destilada, propilenoglicol, solução salina, para aumentar seu poder de dissolução e ação. 6,34,36

Aliado a suas propriedades fenólicas e ao íon cloro, o paramonoclorofenol detém um grande potencial antimicrobiano. A associação com outras substâncias tem sido proposta com o objetivo de aumentar esse potencial. Pode ser combinado à cânfora para reduzir o seu efeito irritativo, formando uma mistura líquida 
denominada PMCC (Paramonoclorefenol Canforado). Assim como o hidróxido de cálcio, - PMCC tem ação limitada, pois só age por contato e por ter a capacidade de coagular matéria orgânica residual, sendo necessário que o canal esteja totalmente limpo e seco. Pela baixa tensão superficial, é indicado em casos de canais atrésicos em que a inserção do hidróxido de cálcio é dificultada. ${ }^{35}$

A cânfora presente no PMCC é um óleo com baixa solubilidade em água que permite a liberação lenta dos íons de hidroxila da pasta de hidróxido de cálcio com o intuito de potencializar o efeito antimicrobiano, além de aumentar o poder de escoamento. Devido ao $\mathrm{pH}$ alcalino, ocasionam uma desnaturação proteica superficial do tecido em contato com a pasta que auxilia como uma barreira física para difusão, retardando a reinfecção do canal. É biocompatível e destroem células bacterianas em curto período. Em junção, possuem amplo espectro de ação e se apresentam como excelente alternativa como atividade antibacteriana e antifúngica. ${ }^{36}$

Utilizada isoladamente ou associada ao hidróxido de cálcio, a clorexidina responde aos requisitos de baixa toxicidade e atividade antimicrobiana, sendo capaz de difundir nos túbulos dentinários. Tanto o hidróxido de cálcio quanto a clorexidina exercem efeito bactericida pela desintegração da membrana. A adição da clorexidina ao hidróxido de cálcio é capaz de induzir a formação de espécies reativas de oxigênio que podem inibir o crescimento bacteriano do enterococcus faecalis, pela destruição da parede celular e da membrana plasmática mediada por óxido nítrico. ${ }^{37}$

\section{Discussão}

A infecção intracanal é uma das principais responsáveis pela sintomatologia dolorosa persistente em pacientes, denominada infecção primária. Nesses casos, é necessária uma intervenção profissional para que o sistema de canais radiculares, colonizados por micro-organismos, seja devidamente limpo para a regressão dos danos pulpares e perirradiculares. ${ }^{3,8}$ Quando a terapêutica endodôntica não é eficaz na neutralização da microbiota, essa infecção se torna persistente. ${ }^{37}$ Há uma predominância de espécies isoladas gram positivas, anaeróbias e anaeróbias facultativas. Esses micro-organismos colonizam na complexidade dos canais radiculares, como em istmos, deltas apicais, canais acessórios e túbulos dentinários, resultando em falhas no tratamento devido à ineficiência do preparo químico mecânico, volume, fluxo da solução irrigadora e medicação intracanal na eliminação do biofilme. 3,8,38,39,40

O enterococcus faecalis, espécie gram positiva anaeróbia facultativa, tem sido relatado como a espécie de maior prevalência em dentes já tratados endodonticamente, e que resultaram em insucesso, com taxas de até $90 \% .^{3,4,40}$ Alguns estudos apontaram a capacidade do enterococcus faecalis em formar biofilme sobre condições limitantes em $\mathrm{PH}$ alcalino e crescimento em temperaturas que chegam a $60^{\circ} \mathrm{C}$, sendo características que o tornam persistente e resistente. ${ }^{5,6}$ Possui, por sua vez, mecanismos de resistência que causam alterações fisiológicas e estruturais da célula bacteriana como forma de defesa frente aos agentes antimicrobianos. ${ }^{7}$

O hidróxido de cálcio é a medicação mais usada no tratamento dos canais radiculares. Como resultado da dissociação dos íons cálcio e hidroxila, agem causando danos à membrana, ao DNA bacteriano e desnaturação proteica das bactérias. Porém, apresentam baixa fusão e solubilidade, agindo apenas por contato. ${ }^{6}$ O enterococcus faecalis utiliza a bomba de prótons que mantém o ph ácido no interior da célula bacteriana e dificulta a alcalinização conferindo, dessa forma, resistência.5,6,11 Como forma de aumentar o efeito dessa 
medicação, Duarte et al. (2018) realizaram um estudo em que foi avaliado o efeito da ativação ultrassônica do hidróxido de cálcio. ${ }^{38}$ Houve uma maior penetração da medicação nos túbulos dentinários, proporcionando um aumento nos níveis do ph, favorecendo a atividade antimicrobiana.

Como principais irrigantes utilizados na eliminação do enterococcus faecalis, se destacam o hipoclorito de sódio e a clorexidina. O hipoclorito de sódio, por sua vez, atua como um solvente da matéria orgânica, transformando a matéria em substância solúvel facilmente eliminada na aspiração. Em um estudo para avaliar a eficácia do hipoclorito de sódio em dentes previamente contaminados por cepas de enterococcus faecalis, o crescimento bacteriano foi considerado nulo, sendo este, eficaz contra esse micro-organismo. ${ }^{39}$ Entretanto, quando usado em altas concentrações, maior o seu efeito bactericida e maior o potencial de agredir os tecidos periapicais, ${ }^{15}$ além de apresentarem toxicidade aos tecidos vitais, tendo como resultado ulceração e necrose em casos de contato com mucosas. Em forames apicais amplos ou dentes com rizogênese incompleta, pode haver acidentes e complicações como o extravasamento dessa substância aos tecidos periapicais, provocando manifestações clínicas imediatas como edema e dor intensa. ${ }^{42}$

Na mesma linha de raciocínio, a clorexidina possui um amplo espectro de ação, age em bactérias gram negativas, positivas eleveduras. Em razão da sua propriedade catiônica, é capaz de manter a sua substantividade por horas após sua aplicação e, também, pela relativa ausência de citotoxidade tem sido citada como irrigante alternativo, principalmente em relação à sua bicompatibilidade ou em casos de reação alérgica ao hipoclorito de sódio. ${ }^{38}$ Estudos não apontaram diferença significativa entre os dois irrigantes como ação antibacteriana. ${ }^{15,39,43}$ Já em um estudo mais recente utilizando três metodologias diferentes como: avaliação microscópia com o Optical Coherence Tomography, confocal e por Low Load Compression Testing em que foi feita uma comparação sobre a influência do hipoclorito de sódio e a clorexidina sobre a estrutura do biofilme, o hipoclorito de sódio mostrou a melhor eficácia contra o biofilme, e a clorexidina se revelou inefetiva, além de possuir a capacidade de causar um rearranjo na estrutura do biofilme, tornando este menos efetivo. ${ }^{44}$

A clorexidina não apresenta características tóxicas aos tecidos como o hipoclorito de sódio, entretanto, não possui a capacidade de dissolução da matéria orgânica. Tanto a clorexidina quanto o hipoclorito de sódio são incapazes de remover totalmente a smear layer. Dessa forma, faz-se necessário o uso do EDTA que age sobre tecidos inorgânicos e promove a efetiva remoção da smear layer. ${ }^{16,17}$

Como forma de potencializar a ação das soluções irrigadoras no interior do canal radicular, a irrigação ultrassônica passiva é capaz de atingir áreas inacessíveis à instrumentação e faz que a substância química flua no SCR por meio de agitação física capaz de causar perturbação ao biofilme bacteriano. ${ }^{19,20,41}$ No entanto, a ocorrência efetiva é dependente da intensidade de energia do dispositivo, o espaço livre dentro do canal e a total ausência de interferência na ponta. Por causa das características anatômicas do canal radicular, a ativação ultrassônica é menos eficaz na região apical do que na região cervical. $^{22}$

Ao que se refere à eficácia da PUI, existem divergências na literatura. Em um estudo realizado por Tanomaru et al. (2015) com diferentes métodos para avaliar a eficiência da irrigação, todos os grupos de estudo apresentaram resultados semelhantes, não havendo diferença significante quanto à utilização ou não da irrigação ultrassônica 
passiva. ${ }^{19}$ Já em um estudo in vitro, em que dentes humanos foram extraídos e contaminados por enterococcus faecalis, houve uma redução de $100 \%$ utilizando a irrigação ultrassônica passiva. ${ }^{21}$

Para avaliar a eficácia de um novo sistema de irrigação, Easy Clean, em comparação à irrigação ultrassônica passiva foi possível observar que a eliminação de detritos da porção apical do SCR foi maior quando utilizado o easy clean. ${ }^{22}$ Também, em um estudo para avaliar a capacidade de dissolução de matéria orgânica, o easy clean exerceu maior eficácia. Entretanto, não houve a total dissolução da matéria orgânica em qualquer dos sistemas de irrigação usados. ${ }^{25}$

Assim como o easy clean, oXP endo finisher representa um método auxiliar e eficaz. Em contato com a temperatura corporal, assume uma forma de colher para que o instrumento tenha contato com as paredes do canal. ${ }^{26,27}$ No terço apical, quando utilizado o sistema XP endo finisher, os canais se apresentam com menos detritos. ${ }^{27}$ Diante dessas premissas, a irrigação ultrassônica passiva easy clean e o XP endo finisher representam uma ferramenta auxiliar e complementar no processo de limpeza do SCR. Porém, sugerem-se novos estudos para avaliar a capacidade dos sistemas na descontaminação, incluindo áreas de istmos e ramificações em geral como canais acessórios e, avaliar possíveis resultados adversos, como extrusão de detritos apical.

Também como coadjuvante na eliminação desse patógeno, a terapia fotodinâmica se apresenta como uma técnica promissora. Em um estudo contendo tubos inoculados com enterococcus faecalis a terapia fotodinâmica exerceu efeito bacteriostático havendo, portanto, apenas uma redução no número de células bacterianas e não a sua eliminação. ${ }^{45}$ Assim, Silva et al. (2010) também relataram uma redução do enterococcus faecalis, mas não a sua eliminação. ${ }^{46}$ Devido às variações utilizadas em literatura, como tempo de irradiação e diferentes fotossensibilizadores, há uma dificuldade na comparação entre os estudos e estabelecimento de um protocolo clínico padrão, permanecendo assim como temas controversos.

\section{CONSIDERAÇÕES FINAIS}

Partindo desses pressupostos, é possível afirmar que há uma redução no número, mas não a erradicação total de enterococcus faecalis. É a espécie de maior prevalência nos casos de infecções endodônticas secundárias e persistentes. $\mathrm{O}$ enterococcus faecalis possui a habilidade de penetrar nos túbulos dentinários, formar biofilme e apresenta capacidade de sobreviver em condições limitantes com escassez de nutrientes. A ação mecânica dos instrumentos e a química das soluções irrigadoras e medicações são essenciais para a eliminação desses patógenos.

Por não apresentarem características de dissolução da matéria orgânica e por se mostrarem menos eficaz na eliminação do biofilme, a clorexidina pode ser substituída pelo hipoclorito de sódio como solução irrigadora na eliminação desses patógenos. Com o propósito de minimizar a ocorrência de extravasamento e danos periapicais, alguns cuidados devem ser adotados com o uso do hipoclorito de sódio, como concentração da substância, irrigação lenta e simultânea aspiração.

Como métodos auxiliares na descontaminação dos canais radiculares, as soluções irrigadoras podem ser agitadas no interior do SCR pelos sistemas easy clean, XP endo finisher e irrigação ultrassônica passiva, exibindo assim, resultados promissores na eliminação dos detritos radiculares. Os canais se apresentam mais limpos no terço apical quando utilizados os sistemas XP endo finisher e easy clean.

A terapia fotodinâmica tem demonstrado resultados promissores como coadjuvante 
na terapêutica endodôntica, capaz de potencializar a descontaminação do SCR. Novos estudos precisam ser realizados, sendo que os mecanismos de defesa do patógeno já estão descritos e elucidados. Por meio de novos estudos, poderá se estabelecer protocolos padrões para sua incorporação.

\section{REFERÊNCIAS}

1. Silva FC, Freitas RP, Lourenço APA, Braga $A C R$, Jorge $A O C$, Oliveira LD, et al. Análise da efetividade da instrumentação associada à terapia fotodinâmica antimicrobiana e a medicação intracanal na eliminação de biofilmes de Enterococcus faecalis. Braz Dent Sci 2010; 13 (5): 31-8. http://ojs.ict.unesp.br/ index.php/cob/article/viewFile/11/575

2. Siqueira JF Jr, Rôças IN, Ricucci D., Hülsmann M. Causes and management of post-treatment apical periodontitis. BDJ 2014; 216 (6): 305-12. https://www.ncbi. nlm.nih.gov/pubmed/24651336

3. Lacerda MFLS, Coutinho TM, Barrocas D., Rodrigues JD, Vidal F. Infecção secundária e persistente e sua relação com o fracasso do tratamento endodôntico. Rev. Bras. Odontol. 2016; 73 (3): 2127. http://revista.aborj.org.br/index.php/rbo/ article/view/732

Siqueira JF JR., Rôças I N. Present status and future directions in endodontic microbiology. Endod Topics 2014; 30 (1): 3-22. https://onlinelibrary.wiley.com/doi/ 10.1111/etp. 12060

4. Zandoná J., Souza MA. Características microbiológicas, patogenicidade e viabilidade do Enterococcus faecalis e seu cultivo in vitro em pesquisasmicrobiológicasnaáreadaEndodontia. RFO 2017; 22 (2): 255-60. http://seer.upf. br/index.php/rfo/article/view/7225

5. Sousa MN, Macedo AT, Santos JRA. Interrelação entre Enterococcus faecalis, Candida albicans e os tratamentos endodônticos. Rev. Investig Biomed 2017; 9 (1): 49-57. http:// www.ceuma.br/portalderevistas/index.php/RIB/ article/view/87/pdf
6. Di Santi BT, Ribeiro MB, Endo MS, Gomes BPFA. Avaliação da suscetibilidade antimicrobiana de bactérias anaeróbias facultativas isoladas de canais radiculares de dentes com insucesso endodôntico frente aos antibióticos de uso sistêmico. Rev. Odontol UNESP 2015; 44 (4): 200-206. http://www.scielo.br/pdf/rounesp /v44n4/1807-2577-rounesp-44-4-200.pdf

7. Siqueira JF JR., Roças IN. Distinctive features of the microbiota associated with different forms of apical periodontitis. Journal of Oral Microbiology 2009; 1 (0). https://www.ncbi. nlm.nih.gov/pubmed/21523208

8. Kayaoglu G., Erten H., Bodrumlu E., Orstavik D. The Resistance of Collagen-associated, Planktonic Cells of Enterococcusfaecalis to Calcium Hydroxide. J Endod 2009; 35 (1): 46-49. https://www.ncbi.nlm.nih.gov/ pubmed/19084123

9. Nacif MCAM, Alves FRF. Enterococcus faecalis na endodontia: um desafio ao sucesso. Rev. Bras. Odontol 2010; 67 (9): 209-214. http://revista.aborj.org.br/index. php/rbo/article/view/195/190

10. Andrade AO, Scelza MFZ, Guaraldi ALM. Isolamento e identificação de Enterococcus $s p$ em infecções endodônticas primárias. Rev. Bras. Odontol 2011; 68 (1): 20-24. http://revista. aborj.org.br/index.php/rbo/article/view/245/212

11. Pretel H., Bezzon F., Faleiros FBC, Dametto FB, Vaz LG. Comparasion between irrigants solutions in endodontics: chlorhexidine $x$ sodium hypocloride. Rev. Gaucha. Odontol 2011; 59 (0): 127-132. http://www.scielo.br/scielo.php? script=sci_arttext\&pid=S180683242017000100 298\&lng=en\&tlng=en

12. Neris GWD, Arruda MF, Duque TM, Neris CKD, Galindo JKSN. O hipoclorito de sódio e seus conceitos de aplicabilidade na endodontia. Rev. Uningá 2015; 24 (3): 95-100. http://revista. uninga.br/index.php/uningareviews/article/ view/1729

13. Fidalgo TKS, et al., Citotoxidade de diferentes concentrações de hipoclorito de sódio sobre osteoblastos humanos. RGO 2009; 57 (3): 317-321. http:// www.revistargo.com.br/viewarticle.php?id=853 
14. Santos TL, DallMagro E., DallMagro AK, Corrêa B., Fronza BM, Colla F. Ação antimicrobiana do hipoclorito de sódio a $2,5 \%$ e clorexidin gel $2 \%$ em raízes contaminadas com Enterococcus faecalis. RFO 2012; 17 (2): 150-155. http:// revodonto.bvsalud.org/scielo.php?script=sci_ar ttext\&pid=S141340122012000200005\&lng=pt\& $\mathrm{nrm}=\mathrm{iso} \&$ tlng $=\mathrm{pt}$

15. Haapasalo M., Shen Y., Qjan W., Gao Y. Irrigation in Endodontics. Dent Clin 2010; 54: 291-312. https://www.ncbi.nlm.nih.gov/ pubmed/24651335

16. Mafra SC, Girelli CFM, Xavier VFG, Lacerda MFL, Lacerda GP, Coelho RG. A eficácia da solução de EDTA na remoção de smear layer e sua relação com o tempo de uso: uma revisão integrativa. RFO 2017; 22 (1): 120-129. http:// docs.bvsalud.org/biblioref/2017/08/848734/ artigo20.pdf

17. Rodrigues MIQ, Frota MA, Frota LMA. Uso da irrigação ultrassônica passiva como medida potenciadora na desinfecção do sistema de canais radiculares - revisão de literatura. Rev. Bras. Odontol 2016; 73 (4): 320-324. http://revista.aborj.org. br/index.php/rbo/article/view/778/0

18. Tanomaru JMG, Andrade GMC, Faria NB JR, Watanabe E, Filho TM. Effect of Passive Ultrasonic Irrigation on Enterococcus faecalis from Root Canals: An Ex Vivo Study. Brazilian Dental Journal 2015; 26 (4): 342-346. http://www.scielo.br/ scielo.php? script=sci_arttext\&pid $=$ S0103-64402015000400342

19. Souza MA, Dias CT, Zandona J., Hoffman IP, Menchik VHS, Palhano HS, et al. Antimicrobial activity of hypochlorite solutions and reciprocating instrumentation associated with photodynamic therapy on root canals infected with Enterococcus faecalis - an in vitro study. Photodiagnosis and Photodynamic Therapy 2018; 23: 347-352. https://www.ncbi.nlm.nih. gov/pubmed/30053480

20. Jiménez L., Gómez J., Matos M. Irrigación ultrasónica pasiva comparada con irrigación manual en la eliminación del enterococcus faecalisdelsistemadeconductos(estudioinvitro).
Acta Odont. Venez. 2014; 52 (2). https://www. actaodontologica.com/ediciones/2014/2/art-9/

21. Kato AS, Cunha RS, Bueno CES, Pelegrine RA, Fontana CE, Martin AS. Investigation of the Efficacy of Passive Ultrasonic Irrigation Versus Irrigation with Reciprocating Activation: An Environmental Scanning Electron Microscopic Study. JOE 2016; 42 (4): 659-663. https://www. ncbi.nlm.nih.gov/pubmed/26906240

22. Rodrigues CT, Duarta MAH, Guimarães BM, Vivan RR, Bernardineli N. Comparasion of two methods of irrigant agitation in the removal of residual filing material in retreatment. Braz. Oral Res 2017; 31: e-113. https://www.ncbi.nlm. nih.gov/pubmed/29267674

23. Duque JA, Duarte MAH, Canali LCF, Zancan RF, Vivan RR, Bernardes RA. Comparative Effectiveness of New Mechanical Irrigant Agitating Devices for Debris Removal from the Canal and Isthmus of Mesial Roots of Mandibular Molars. JOE 2017; 43 (2): 326-335. https://www. ncbi.nlm.nih.gov/pubmed/27989584

24. Nunes KS, Feron L., Montagner F., Melto TAF. Analysis of root canal organic tissue dissolution capacity according to the type of irrigation solution and agitation technique. Braz J Oral Sci. 2016; 16 (1): 70-74 https://www.fop.unicamp.br/ bjos/index.php/bjos/article/view/1190

25. Alves FRF, Andrade CV JR, Alves MFM, Perez AR, Roças IN, Versiani MA, et al. Adjunctive Steps for Disinfection of the Mandibular Molar Root Canal System: A Correlative Bacteriologic, Micro-Computed Tomography, and Cryopulverization Approach. JOE 2016; 1-6. https://www.ncbi.nlm.nih.gov/ pubmed/27641947

26. Bao P., Shen Y., Lin J., Haapasalo M. In Vitro Efficacy of XP-endo Finisher with 2 Different Protocols on Biofilm Removal from Apical Root Canals. JOE 2017; 43 (2): 321-326. https:// www.ncbi.nlm.nih.gov/pubmed/27939826

27. Zand V., Mokhtari H., Reyhani MF, Nahavandizadeh N., Azimi S. Smear layer removal evaluation of different protocol of Bio Race file and XP-endo Finisher file in corporation with EDTA $17 \%$ and $\mathrm{NaOCl}$. J Clin Exp Dent. 2017; 9 (11): 1310-1314. https://www.ncbi.nlm. nih.gov/pubmed/29302283 
28. Leoni GB, Versiani MA, Sousa TS, Bruniera JFB, Pecora JD, Neto MDS. Ex vivo evaluation of four final irrigation protocols on the removal of hard-tissue debris from the mesial root canal system of mandibular first molar. International Endodontic Journal 2016; 50 (4): 398-406. https://www.ncbi.nlm.nih.gov/ pubmed/26992452

29. Azim AA, Aksel H., Zhuang Tm Mashtare T., Babu JP, Huang TJ. Efficacy of 4 irrigation protocols in killing bacteria colonized in dentinal tubules examined by a novel confocal laser scanning microscope analysis. Journal of endodontics 2016; 42 (6): 928-934. https:// www.ncbi.nlm.nih.gov/pubmed/27130334

30. Delboni M. Terapia fotodinâmica em canais infectados com Enterococcus faecalis: revisão de literatura. RFO 2017; 22 (2): 261-270. http://docs.bvsalud.org/biblioref/ 2018/01/877849/7397-24659-1-pb.pdf

31. Garcez A., Roque J., Murata W., Hamblin M. Uma nova estratégia para PDT antimicrobiana em Endodontia. Rev Assoc Paul Cir Dent 2016; 70 (20): 126-130. http://revodonto.bvsalud.org/ $\mathrm{pdf} / \mathrm{apcd} / \mathrm{v} 70 \mathrm{n} 2 / \mathrm{a} 05 \mathrm{v} 70 \mathrm{n} 2 . \mathrm{pdf}$

32. Eduardo CP, Silva MSB, Ramalho KM, Lee RML, Aranha ACC. A terapia fotodinâmica como benefício complementar na clínica odontológica.

Rev Assoc Paul Cir Dent 2015; 69 (3): 226-235. http://revodonto.bvsalud.org/pdf/ apcd/v69n3/a04v69n3.pdf

33. Nery M., Cintra LTA, Gomes JE JR, Dezan ELOI JR, Otoboni JA JR, Araujo GS, et al. Estudo longitudinal do sucesso clínico-radiográfico de dentes tratados com medicação intracanal de hidróxido de cálcio. Rev. Odontol UNESP 2012; 41 (6): 396-401. http://www.scielo.br/pdf/ rounesp/v41n6/a05v41n6.pdf

34. Carvalho MGP, Dotto SR, Brondani GC, Filter VP, Kist PP. Reparo de lesão periapical: relato de caso. Revista de Endodontia pesquisa 2012; 9 (15). http://w3.ufsm.br/endodontiaonline/ artigos/[REPEO]\%20Numero\%2015\%20 Artigo\%201.pdf

Siqueira JF JR, et al., Princípios biológicos do tratamento endodôntico de dentes com polpa necrosada e lesão perirradicular. Rev. Bras.
Odontol. 2012; 69 (1): 8-14. http://revodonto. bvsalud.org/pdf/rbo/v69n1/a04v69n1.pdf

35. Vasconcelos LRSM, Midel RZ, Minotti PG, Pereira TC, Duarte MAH, Andrade FB. Effect of ultrasound streaming on the disinfection of flattened root canals prepared by rotary and reciprocating systems. J Appl Oral Sci 2017; 25 (5): 477-482. https://www.ncbi.nlm.nih.gov/ pubmed/29069144

36. Rocha TAF, Cerqueira JDM, Carvalho DS. Infecções endodônticas persistentes: causas, diagnóstico e tratamento. Revista de ciências médicas e biológicas 2018; 17 (1): 78-83. https://portalseer.ufba.br/index.php/cmbio/ article/view/23276

37. Rosa CCS, Araújo CV, Carvalho MFF, Araújo PV. Estudo piloto da análise comparativa da atividade antimicrobiana da PDT e agentes irrigantes em canais radiculares inoculados com Enterococcus faecalis "in vitro". Arq Odontol 2019; 55 (2). https://periodicos.ufmg.br/index. php/arquivosemodontologia/article/view/12363

38. Endo MS, Signoretti FGC, Kitayama VS, Marinho ACS, Martinho FC, Gomes BPFA. Investigation in vivo of Enterococcus faecalis in endodontic retreatment by phenotypic and genotypic methods. Acta Scientiarum Health Sciences 2015; 37 (1): 95-103. http://periodicos. uem.br/ojs/index.php/ActaSciHealthSci/article/ view/24348

39. Duarte MAH, Balan NV, Zeferino MA, Vivan RR, Morais CAH, Filho MT. Effect of Ultrasonic Activation on $\mathrm{pH}$ and Calcium Released by Calcium Hydroxide Pastes in Simulated External Root Resorption. J Endod 2012; 38 (6): 834-837. https:// www.ncbi.nlm.nih.gov/pubmed/22595121

40. Santos ACA, Borges L., Porto ARNP. Acidentes e complicações na endodontia com o uso do hipoclorito de sódio. Ciência atual 2017; 10 (2): 02-08. http://www.cnad. edu.br/revista-ciencia-atual/index.php/cafsj/ article/view/197

41. Gomes CC, Camões ICG, Freitas LF, Pinto SS, Saraiva SM, Sambati S. Avaliação do hipoclorito de sódio e da clorexidina na desinfecção de cones de guta-percha. Revista de Odontologia da Universidade Cidade de 
São Paulo 2010; 22 (2): 94-103.http://arquivos. cruzeirodosuleducacional.edu.br/principal/old/ revista_odontologia/pdf/maio_agosto_2010/ unicid_22_02_94_103.pdf

42. Busanello F.; Petridis X.; So MVR; Dijkstra RJB; Sharma PK; Van Der Sluis LWM. Chemical biofilm removal capacity of endodontic irrigants as a function of biofilm structure: optical coherence tomography, confocal microscopy and viscoelasticity determination as integrated assessment tools. International Endodontic Journal 2019; 52(0): 461-474. https://www. rug.nl/research/portal/files/83379876/Busanello _et_al_2019_International_Endodontic_ Journal.pdf

43. Sebrão CC, Bezerra Jr AG, de França PH, Ferreira LE, Wes-tphalen VP. Comparison of the efficiency of rose bengal and ethylene blue as photosensitizers in photodynamic therapy techniques for Enterococcus faecalis inactivation. Photomed Laser Surg 2017; 35 (1): 18-23. https://www.ncbi.nlm.nih.gov/pubmed/ 27617768

44. Silva FC, Freitas LRP, Lourenço APA, Braga ACR JR, Jorge AOC, Oliveira LD, et al. Análise da efetividade da instrumentação associada à terapia fotodinâmica antimicrobiana e a medicação intracanal na eliminação de biofilmes de Enterococcus faecalis. Bras Dent Sci 2010; 13 (5): 31-38. http://ojs.ict.unesp.br/ index.php/cob/article/viewFile/11/575

Submetido em: 6-6-2019

Aceito em: 29-7-2020 